\title{
Flow theory: Advancing the two-dimensional conceptualization
}

\author{
Raymond Lavoie $^{1}$ (1) $\cdot$ Kelley Main ${ }^{2} \cdot$ Anastasia Stuart-Edwards $^{3}$
}

Accepted: 5 October 2021 / Published online: 5 November 2021

(c) The Author(s) 2021

\begin{abstract}
This research advances the conceptualization and measurement of flow. The results of six studies $(N=2809)$ reveal that flow has two dimensions: "fluency," which is comprised of experiences related to fluent thought and action; and "absorption," which is based on sustained full attention. The results also demonstrate that the two dimensions have nuanced relationships with other variables. Specifically, while the fluency dimension is related to antecedents of flow (familiarity, skill, progress), the absorption dimension is not. Conversely, the absorption dimension was found to be strongly related to consequences of flow (behavioral intentions, presence), while the fluency dimension was not. Furthermore, we demonstrate that fluency-related experiences can give rise to the absorption-related experiences, which advances our understanding of how flow emerges. Finally, we develop a refined measure of flow called the two-dimensional-flow scale, and demonstrate its enhanced ability to capture variance in flow and other related variables in leisure contexts.
\end{abstract}

Keywords Flow $\cdot$ Absorption $\cdot$ Fluency $\cdot$ Presence $\cdot$ Scale development

\section{Introduction}

Flow manifests as a state of seemingly effortless concentration wherein one is completely absorbed in what they are doing (Csikszentmihalyi, 1975), and can arise during a wide range of daily activities, including work, physical activity, technology use, and interactions with others (Aubé et al., 2014; Eisenberger et al., 2005; Kawabata \& Mallett, 2011; Mathwick \& Rigdon, 2004; Moneta, 2012). Flow offers a compelling line of inquiry given the myriad positive outcomes that have been associated with it, including optimized levels of engagement, performance, and enjoyment (Christandl et al., 2018; Moneta, 2017; Smith \& Sivakumar, 2004). In an attempt to leverage these benefits, researchers have identified and examined several antecedents to flow,

Raymond Lavoie

lavoier@merrimack.edu

Kelley Main

Kelley_main@umanitoba.ca

1 Merrimack College, 315 Turnpike Street, North Andover, MA 01845, USA

2 University of Manitoba, 181 Freedman Crescent, Winnipeg, MB R3T 5V4, Canada

3 University of Lethbridge, 4401 University Drive, Lethbridge, AB T1K 6T5, Canada including contextual factors, personality differences, and task characteristics (Baumann \& Scheffer, 2011; Baumann et al., 2016; Engeser \& Rheinberg, 2008; Schüler et al., 2013).

Despite these efforts, there remains confusion regarding the conceptualization of flow, including its dimensionality. Nascent work suggests that the various experiences that characterize flow can be grouped into two dimensions: fluency and absorption (Engeser, 2012; Rheinberg et al., 2003). However, researchers have almost exclusively treated flow as unidimensional (e.g., Baumann et al., 2016; Schüler, 2010). While recent work has provided support for the two-dimensional structure of flow (e.g., Lavoie \& Main, 2019a), this conceptualization is still in its infancy and requires further development. Specifically, further research is needed to support the descriptive accuracy and benefits of a two-dimensional conceptualiztion. The exact nature of flow-including its underlying cognitive and affective process-also requires explication.

The present research attempts to address these concerns through a series of studies that utilize a range of leisure activities. First, factor analysis of existing flow measures reveals that a two-dimensional structure is superior to a unidimensional structure, and that these two dimensions have nuanced relationships with other variables. In particular, our findings establish that several known antecedents 
of flow (e.g., skills, familiarity) are related to its fluency dimension, but not its absorption dimension. Conversely, the consequences of flow, such as behavioral intentions and presence, are related to its absorption dimension. We also provide evidence of the relationship between the two dimensions by showing that fluency-related experiences mediated the emergence of absorption-related experiences in the leisure activities used in our studies.

Our results also further clarify the two dimensions of flow based on existing constructs and their underlying psychological processes. Most notably, our findings suggest that the fluency dimension of flow entails the subjective experience of fluency (i.e., ease) and control, and is based on both fluent action and fluent thought. This insight is important given the conceptual similarity to processing fluency, which is defined as the "conscious experience of processing ease, low effort, and high speed" (Winkielman et al., 2003, p. 193). Our results suggest that processing fluency is an important aspect of flow's fluency dimension, as it underlies the subjective experience of fluent thought. Furthermore, our findings also provide empirical support for theorizing which posits that sustained full attention underlies the absorption dimension of flow (Dietrich, 2004) and its emergent nature (Lavoie \& Main, 2019a).

Clarifying the nature of the fluency dimension and demonstrating its importance in the emergence of flow can change how we think about fostering flow. Our findings reveal the importance of subjective ease, which advances earlier theorizing that flow is best achieved via highly challenging tasks (Csikszentmihalyi, 1975). The discrepancy is likely due to the fact that the present research explores flow within the context of leisure activities, whereas original flow theory focused on deepflow states in tasks that are more complex and of longer duration (Lavoie \& Main, 2019a). This explanation is consistent with emerging evidence that flow states and their consequences differ based on the nature of the activities that elicit them (Engeser \& Baumann, 2014), and it advances the literature by suggesting that entry to flow differs depending on the context (e.g., leisure versus work) (Engeser \& Rheinberg, 2008).

Furthermore, we refine the two-dimensional conceptualization and the existing measures of flow in order to capture these dimensions more accurately. To this end, we develop a new measure called the two-dimensional flow scale (TDFS) and demonstrate its ability to capture greater variance in flow and its consequences compared to the unidimensional conceptualization and existing measures. Clarifying flow's dimensionality is important from both a theoretical and measurement standpoint (see Engeser, 2012; Schiefele, 2013; Schiefele \& Raabe, 2011 for further discussion).

Finally, our findings indicate that a match between one's skill level and the demands of a task is not a particularly strong indicator of either dimension of flow, which builds on research suggesting that it is necessary to look beyond this relationship in capturing flow (e.g., Baumann et al., 2016). This result is also consistent with research demonstrating that occurrence of flow in experiential activities, which are not typically associated with challenge (e.g. Lavoie \& Main, 2019b; Novak et al., 2003). Together, these findings advance flow theory and provide a foundation for future research.

\section{The dimensionality of flow}

An important yet largely overlooked fact is that flow states differ in intensity and duration based on the activities that elicit them. As such, it is useful to think of flow states as falling on a continuum, with those elicited by relatively simple activities (e.g., washing dishes) on one end, and those elicited by highly complex activities (e.g., painting a masterpiece, playing professional sports) on the other. Flow is generally thought of in relation to relatively complex activities that are intense and long in duration; this type of flow is often referred to as deepflow (Csikszentmihalyi, 1975). However, flow can also be elicited by shorter experiences that are less intense, yet more common; this type of flow is referred to as microflow (Lavoie \& Main, 2019a). While flow theory and most subsequent theorizing has been based on deepflow, research on flow, including the scales that have been developed to measure it, has almost exclusively investigated flow elicited by relatively shorter, less complex tasks, or what could most properly be considered microflow states. We recognize the importance of distinguishing between types of flow states, and we therefore stipulate that this research focuses on those that fall on the microflow region of the continuum in the context of leisure activities. Given this focus, the terms, "flow," and, "microflow," will be used interchangeably for the remainder of this paper.

The characteristics of flow originally identified by Csikszentmihalyi (1975) refer to an intrinsically rewarding experience defined by clear goals, unambiguous feedback, congruence between skills and task demands, the ability to concentrate on and exhibit control over the task at hand, a sense of merging between action and awareness, a loss of self-consciousness, and a distorted perception of time. However, there is disagreement regarding the dimensionality of these nine characteristics and the subsequent conceptualization of flow. While most research utilizes a unidimensional conceptualization of flow (Martin \& Jackson, 2008; Schiefele, 2013), other findings suggest that the nine characteristics are driven by similar underlying mechanisms (Dietrich, 2004). There is further disagreement about the underlying experiences of flow among proponents of a multidimensional conceptualization; while some suggest that flow has three primary experiences-namely, centering of attention, loss of self-consciousness, and the merging of action and 
awareness (Csikszentmihalyi \& Csikszentmihalyi, 1988; Moneta, 2017) —others argue that flow is best described by two distinct sets of experiences (Engeser, 2012).

Despite these disagreements, empirical investigations of the dimensionality of flow have been limited. We seek to fill this gap in the literature by empirically exploring the dimensionality of flow across a wide variety of leisure tasks. We begin by evaluating various existing measures to determine which are most suitable for assessing a wide range of activities. Findings have demonstrated that flow varies in degree, and this has motivated the development of various continuous measures, including the global "core flow" scale, which captures a subject's overall feeling of being in flow (Martin \& Jackson, 2008). However, it is not possible to determine the dimensionality of flow without assessing each of the original characteristics of flow identified by Csikszentmihalyi (1975).

Two existing scales were created with this aim in mind. Martin and Jackson's (2008) Flow Short Scale (henceforth referred to as the MJ-FSS) is primarily used in sports contexts and employs wording focused on performance. Rheinberg et al.'s (2003) Flow Short Scale (henceforth referred to as the FSS) was developed for use in a more general psychological context - thus, with less focus on performancemaking it more appropriate for measuring flow across contexts (cf. Engeser \& Rheinberg, 2008). Given that we aim to explore flow in relation to both performance-oriented and experiential consumer-related tasks, we begin our investigation by building on the items on Rheinberg et al.'s (2003) FSS.

We suggest that it is most appropriate to conceptualize flow as consisting of two dimensions. The view that flow is best conceptualized as consisting of three experiences (i.e., centering of attention, loss of self-consciousness, and merging of action and awareness) seems unsuitable, as these experiences can all be explained by the common underlying process of sustained concentration (Dietrich, 2004). Furthermore, this view of flow also overlooks the importance of its characteristic feelings of control and perceived ease. The unidimensional view of flow does not seem suitable either, as flow's characteristic experiences appear to be unique and sometimes conflicting (Baumann \& Scheffer, 2010). For example, experiences related to feeling in control are qualitatively distinct from other flow experiences, such as losing track of time. Perhaps experiences related to concentration (e.g., losing track of time) and fluent processing (e.g., control and ease) become relatively symbiotic over the longer periods of time involved in deepflow. This distinction is important, and it is discussed in greater detail in the General Discussion section of this paper.

We suggest that a two-dimensional conceptualization of flow is most appropriate for microflow states, as it is able to account for all of the critical flow experiences, while also making the necessary distinctions between the sets of experiences within flow, which is not possible with a unidimensional conceptualization. For example, a loss of self-consciousness, the merging of action and awareness, and time distortion are all explained by one underlying attentional process related to concentration (Dietrich, 2004); specifically, focusing on something for an extended period necessarily results in the merging of action and awareness and the centering of attention. Moreover, our limited attentional resources will result in one losing track of time and selfconsciousness (Dietrich, 2003).

The remaining characteristic flow experiences (i.e., perceptions of control, feelings of automaticity, inherent enjoyment) are related but qualitatively distinct from the absorption experiences and can be grouped into a second dimension that is based on things going well. In particular, the remaining flow experiences are all associated with fluent thought and action, and there is empirical evidence supporting the inherent relationships between them. The experiences of fluent thought and action (i.e., processing fluency) both bolster feelings of control (Sidarus et al., 2017). Moreover, fluent cognitive processes such as feelings of automaticity (Bargh, 1994), fluency (Oppenheimer, 2008) and ease (Schwarz, 2004) are inherently enjoyable. Fluent action in the form of progress is also inherently enjoyable, partly because it satisfies one's need to feel competent and self-efficacious (Bandura, 1982; Ryan \& Deci, 2000).

The inherently enjoyable fluency experiences help to explain the autotelic (intrinsically rewarding) aspect of flow. This aspect is especially evident when combined with the nature of the absorption dimension, which suggests that one would have mental "order" and be devoid of any negative thoughts given their complete focus on the task or experience (Csikszentmihalyi, 1975). In summary, we suggest that the two-dimensional conceptualization of flow is most appropriate in succinctly capturing the various experiences that comprise flow while also hinting at the underlying processes.

Hypothesis 1: Flow has a two-dimensional structure.

\section{Relationships with other variables}

We build on our two-dimensional hypothesis by exploring the relationship between the two dimensions of flow, as well as some of their antecedents and consequences (see Fig. 1). We theorize that the two dimensions of flow will have nuanced relationships with antecedents and consequences. Demonstrating relationships of varying strength would support the importance of the two-dimensional conceptualization. For example, if a certain dimension had stronger relationships with antecedents it would reveal which aspect of 
Flow's Nomological Network

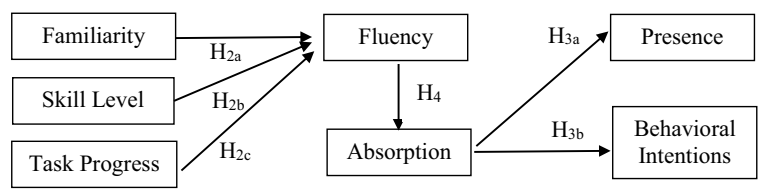

Fig. 1 Flow's nomological network

flow is most important in fostering the state and the process through which flow happens.

\section{Antecedents of flow}

Several antecedents to flow have been demonstrated, with individual's familiarity with a task and their task-based skills being among the most prominent (Schiefele \& Raabe, 2011). For example, researchers have manipulated flow by calibrating players' skillsets in games such as Tetris and Pacman, and then manipulating the difficulty of the game to provide an appropriate level of challenge (Moller et al., 2010). We suggest that one's familiarity with a task will facilitate the fluency-related experiences of flow, as familiarity makes it easier to process task-related information (Song \& Schwarz, 2009). In addition, one's familiarity with a task will result in the representation of its elements in their memory (Bornstein \& D'Agostino, 1992), which will assist the processes of encoding and decoding, thus increasing processing fluency (Mandler et al., 1987).

We argue that flow is not only characterized by fluent thought, but also by fluent action. Similar to the relationship between task familiarity and fluency of thought, we suggest that task skill level is positively related to task fluency. Fluency of action manifests as successful progress through an activity, and, alongside fluency of thought, forms the foundation of flow's fluency dimension. These relationships are particularly evident when considering the flow experiences that comprise the fluency dimension (e.g., feelings of control, automaticity, and confidence in one's knowledge of the task), as these experiences are largely derived from familiarity and skill (Reber et al., 1998) and are manifested in the form of continual progress. If a person is not making fluent progress - and especially if they are doing the opposite by making mistakes - they will feel less in control, less enjoyment, and less ease with respect to the task.

The direct relationships between familiarity, skills, and the absorption-related experiences of flow are less clear. In fact, a high level of skill may have the opposite impact on absorption. Absorption occurs when one devotes their attention to an object or activity over an extended period of time such that the object or activity captures their full awareness
(Agarwal \& Karahanna, 2000). Underload accounts of attention suggest that people tend to disengage when tasks are not stimulating enough to capture or hold their full attention (Manly et al., 1999). When a task is not sufficiently difficult or interesting to capture one's full attention, their mind will begin to process unrelated thoughts (i.e., mind wandering) and become more susceptible to distractions (Smallwood \& Schooler, 2006). This phenomenon may occur among individuals with higher levels of skill and familiarity in a given task, as the information presented to them will likely be less stimulating or challenging, thus resulting in decreased attention and limited absorption. This is consistent with Lavoie and Main's (2019a) findings, which demonstrate that flow experiences related to fluency become stronger as task-related skill increases, but that the opposite effect can be observed for absorption. As an exception, one's general ability to focus on, or their inclination to fully engage in, all activities may facilitate absorption (Baumann \& Scheffer, 2011).

Hypothesis 2a: Task familiarity will have a direct positive relationship with the fluency dimension of flow, but not the absorption dimension.

Hypothesis 2b: Task skill level will have a direct positive relationship with the fluency dimension of flow, but not the absorption dimension.

Hypothesis 2c: Task progress will have a direct positive relationship with the fluency dimension of flow, but not the absorption dimension.

\section{Consequences of flow}

Interestingly, some of the established consequences of flow appear to be more directly related to its absorption dimension rather than its fluency dimension. One noteworthy consequence of flow in digital media contexts (e.g., playing video games) is presence, which is defined as a feeling of being present in a particular virtual computermediated environment rather than the immediate physical environment (Sheridan, 1992). As an attention-based experience, presence is enabled when one focuses on one thing for an extended period such that it becomes reality (Banos et al., 1999). As a state of high engagement in a task, flow has been suggested to be the foundation that enables the experience of presence (Weibel et al., 2008). However, the relationship between flow and presence is strongly attention based, which suggests that it is based on flow's absorption dimension, and not its fluency dimension. As such, we posit that the absorption dimension of 
flow will have a direct positive relationship with presence, but the fluency dimension will not.

Findings have also shown that flow can produce futureoriented consequences, such as increasing one's intentions of engaging with the product or experience that elicited the flow state (Lavoie \& Main, 2019a). Full sustained engagement in something suggests a high degree of interest and enjoyment; this relationship is what motivated Csikszentmihalyi's (1975) seminal investigations of flow, as he believed that these highly engaging experiences provide the key to happiness. The fluency related experiences of flow may also be linked to behavioral intentions, as feelings of automaticity, control, and certainty of what to do are also enjoyable and could therefore lead to further engagement (Chambon \& Haggard, 2012). Nonetheless, we argue that one's desire to engage with a product or experience again is more strongly correlated with their initial level of engagement.

On its own, the fluency dimension may not be a good predictor of engagement intentions, as a high degree of perceived fluency may simply be the result of a task being too easy. However, if fluency is accompanied by sustained absorption, it is possible to be more confident that one will want to engage in the flow-inducing activity again. This is consistent with recent findings, which show that fluency without absorption does not create the level of enjoyment for which flow is known (Lavoie \& Main, 2019a). Thus, while the fluency dimension of flow may be related to positive affective outcomes, we suggest that its relationship to behavioral intentions is relatively weak and depends on whether it is accompanied by absorption-related experiences, as these are the experiences that truly indicate interest and predict behavioral intentions. In summary, we suggest that absorption, not fluency, will have the strongest relationship with behavioral intentions, including future use.

Hypothesis 3a: The absorption dimension of flow will have a strong direct positive relationship with presence, but the fluency dimension will not.

Hypothesis 3b: The absorption dimension of flow will have a strong direct positive relationship with behavioral intentions, but the fluency dimension will not.

To summarize, we suggest that the fluency and absorption dimensions of flow will have differing relationships with other variables. Specifically, antecedents of flow such as familiarity, skill, and task progress will be more directly related to the fluency dimension of flow, while some established consequences of flow, such as feelings of presence and behavioral intentions, will be more directly related to the absorption dimension (see Fig. 1 for the complete model).

\section{Overview of studies}

Given the dearth of empirical research on the dimensions of flow and the experiences that best illustrate them, we aim to empirically validate the two-dimensional conceptualization of flow. In Study 1a, we employ exploratory factor analysis to evaluate the dimensionality of flow based on the items of the FSS (Rheinberg et al., 2003; cf. Engeser \& Rheinberg, 2008). To this end, we ask the participants to engage in either a performance-oriented (completing a Sudoku puzzle, $N=619$ ) or an experiential leisure activity (listening to new music, $N=542$ ). In Study $1 \mathrm{~b}$, we refine the measures of flow to create a 6-item scale, which we refer to as the Two-Dimensional Flow Scale (TDFS). The two-dimensional structure is then confirmed and the TDFS is tested in a different context in Study 2. This is followed by Study 3, which analyzes the discriminant and convergent validity of the two dimensions of the TDFS. In Studies 4 and 5, we examine the TDFS' predictive validity and investigate the antecedents and consequences of both dimensions. The relationship between the two dimensions of flow is also examined in Study 5 .

\section{Study 1a-dimensionality of flow}

Study 1a investigated the dimensionality of flow via performance-oriented and experiential tasks across two samples. Our objective in this study was to determine which flowexperiences best capture the emergent dimension(s) in order to develop a better understanding of their underlying psychological processes. In addition, we also sought to demonstrate that the dimensionality of flow remains consistent across both types of tasks. As noted above, the FSS (Rheinberg et al., 2003) was selected as a continuous measure of flow, and was used to test the dimensionality of flow based on its fit with our broad contexts of interest.

\section{Sample 1 (performance-oriented) participants and procedure}

The participants (619 undergraduate students, $M_{\text {age }}=20.25$, $\mathrm{SD}=2.58,51.5 \%$ male) in this sample were asked to work on a Sudoku puzzle. The size of both samples was determined based on Yong and Pearce's (2013) suggestion of 300 participants as the minimum sample size for valid exploratory factor analysis. Given the exploratory nature of the pretest, we sought to approximately double this minimum threshold in order to minimize error. Flow can be experienced during a variety of performance-oriented tasks that range in duration and relative difficulty. To demonstrate 
that the dimensionality of flow is consistent across such variations, we had the participants work on the Sudoku for either $3(N=191)$ or $8 \mathrm{~min}(N=428)$, and we used two different puzzles: an easy puzzle $(N=308)$ and a moderately difficult puzzle $(N=311)$. In addition, the sample for Study 1a was comprised of participants from different countries (US $N=282$, CDN $N=337$ ). Following the task, the participants were asked to complete the FSS (Rheinberg et al., 2003). The Sudokus and full descriptions of the measures and exclusions from each study are reported in either the manuscript or the Supplementary Appendix.

\section{Sample 2 (experiential) participants and procedure}

Flow is also prevalent in everyday life (Csikszentmihalyi \& Lefevre, 1989), occurring in contexts that are more experiential in nature, such as exploring content online (Novak et al., 2000; Trevino \& Webster, 1992). To test the dimensionality of flow in a common experiential task, we had the participants in this sample listen to music. Specifically, we had them listen to a piece of electronic music for approximately three and a half minutes. The 542 participants $\left(M_{\text {age }}=36.47\right.$, $S D=13.24,49.8 \%$ male $)$ consisted of undergraduate students $(N=420)$ and CrowdFlower panel workers $(N=122)$. As with the performance-oriented sample, the participants were asked to complete the FSS (Rheinberg et al., 2003) when the task was finished.

\section{Statistical analysis}

Exploratory factor analysis (EFA) with promax rotation (kappa =4) was used to explore the dimensionality of flow within the two task conditions, while eigenvalues over one, scree tests, and parallel analysis were used to identify the number of dimensions. Costello and Osborne's (2005) guidelines for best practices were used when determining low-loadings $(\leq .32)$, cross-loadings $(\geq .32)$, and low communalities $(\leq .40)$.

\section{Results}

The eigenvalues and scree tests indicated that flow consisted of two dimensions in both samples. In addition to determining the number of dimensions of flow, the Study 1a also sought to understand the mechanisms that underlie these dimensions. As such, we analyzed which flow experiences were most representative of the dimensions based on the factor loadings and communality coefficients, which can be found in Table 1.

The strongest factor loadings for the first dimension to emerge belonged to the items "I felt that I had everything under control," "My thoughts ran fluidly and smoothly," and "I knew what I was doing each step of the way," which supports our theorizing that many characteristic flow eperiences are the result of fluent action and thought. It is important to note that the loadings were consistent across both task conditions (i.e., performance-oriented and experiential). Given the common underlying mechanism related to fluency, we henceforth follow the theorizing of Rheinberg et al. (2003) and refer to this dimension as "fluency."

The second dimension to emerge was consistent with theorizing that many flow experiences are the result of focusing one's attention on something for an extended period of time (Dietrich, 2004). Due to limited cognitive resources, focusing one's attention on a limited information set for a prolonged period of time will impede the ability to process

Table 1 Study 1a factor loadings

\begin{tabular}{|c|c|c|c|c|c|c|}
\hline \multirow[t]{2}{*}{ Items } & \multicolumn{3}{|c|}{ Sudoku (sample 1) } & \multicolumn{3}{|c|}{ Music (sample 2) } \\
\hline & F & A & $\mathrm{h}^{2}$ & $\bar{F}$ & A & $\mathrm{h}^{2}$ \\
\hline $\mathrm{F}_{1}$. My thoughts ran fluidly and smoothly & .96 & & .76 & .72 & & .62 \\
\hline $\mathrm{F}_{2}$. I had no difficulty concentrating & .51 & & .50 & .68 & & .51 \\
\hline $\mathrm{F}_{3}$. My mind was completely clear & .53 & & .48 & .69 & & .63 \\
\hline $\mathrm{F}_{4}$. My thoughts seemed to happen naturally and on their own & .81 & & .70 & .73 & & .63 \\
\hline $\mathrm{F}_{5}$. I knew what I was doing each step of the way & .87 & & .67 & .92 & & .66 \\
\hline$F_{6}$. I felt that I had everything under control & .89 & & .72 & .85 & & .60 \\
\hline $\mathrm{A}_{1} . \mathrm{I}$ lost track of time & & .67 & .35 & & .88 & .64 \\
\hline $\mathrm{A}_{2}$. I was totally absorbed into the Sudoku/song & .33 & .58 & .66 & .34 & .56 & .63 \\
\hline $\mathrm{A}_{3}$. I was completely lost in thoughts about the Sudoku/song & & .65 & .36 & & .75 & .52 \\
\hline $\mathrm{A}_{4}$. I felt just the right amount of challenge from the puzzle/song & & .34 & .25 & .44 & .37 & .50 \\
\hline$\%$ of variance & $45.5 \%$ & $9.1 \%$ & $54.5 \%$ & $47.2 \%$ & $12.3 \%$ & $59.5 \%$ \\
\hline
\end{tabular}

All extraction communality coefficients are greater than initial communality coefficient; loadings less than .32 are not shown. Principal axis factoring with oblique rotation (promax, kappa=4) was used

$F$ fluency, $A$ absorption, $h 2$ communality coefficient after extraction 
higher-order concepts like the "self" and "time" (Dietrich, 2003). The influence of this relationship is evidenced by the fact that the item, "I lost track of time," had the strongest loading for this dimension across both tasks. Other items that loaded strongly across both tasks included, "I was lost in thoughts related to the task," and "I was totally absorbed in the task," which further supports the full devotion of one's mental resources as an underlying mechanism of this dimension of flow. Given this finding, we again adopt Rheinberg et al.'s (2003) terminology and henceforth refer to this dimension as "absorption."

In an effort to develop a better understanding of the two dimensions, we also examined flow experiences that were less diagnostic, such as those with small contributions (i.e., communality below .40) or instances where there were significant overlaps between the experiences (i.e., crossloadings exceeding 0.32). The results were similar across the samples with some minor differences. All fluency items met the criteria in both samples such that they had no significant overlap with absorption items, they had sufficiently high communality values and they loaded strongly on their respective factor (although, items $\mathrm{F}_{2}$ and $\mathrm{F}_{3}$ had relatively weaker loadings, most notably in the Sudoku sample). These findings suggest that the fluency dimension is represented well by the six items but that some items are less diagnostic.

In the Sudoku sample, all absorption items failed at least one criterion as one item loaded on both dimensions ("I was totally absorbed into the Sudoku") and three items ("I lost track of time", "I was completely lost in thought", and "I felt just the right amount of challenge from the puzzle") had small communality values. However, in the music sample, only two absorption items loaded on both dimensions ("I was totally absorbed into the song" and "I felt just the right amount of challenge"). Together, the results across both samples indicate that two absorption items consistently overlapped too much with the fluency dimension or had a weak relationship with the absorption factor.

\section{Discussion}

The results of Study 1a support a two-dimensional conceptualization of flow and provide clarity regarding the processes underlying these two dimensions. Our findings show that the fluency dimension is comprised of flow experiences related to fluent thought and action, such as those demarcated by a high level of control and a smooth progression of thought, while the absorption dimension is comprised of experiences that arise from focusing one's attention on a limited amount of information for an extended period of time, for example, losing track of time. The results were also consistent across both activities (completing a Sudoku and listening to music), which suggests that flow is most appropriately captured by the two identified dimensions.
Since one of the goals of Study 1a was to distinguish the dimensions of flow and their underlying processes, we also identified flow items that poorly describe the two dimensions. Although this analysis was able to identify two distinct factors, further refinement of the scale could enable an even clearer distinction between the fluency and absorption dimensions. In Study 1b, we revise two absorption items to create new ones that more appropriately represent experiences related to the dimensions of flow. Specifically, we suggest removing the two absorption items that failed the criteria in both samples by overlapping with the fluency dimension ("I was totally absorbed into the Sudoku/song" and "I felt just the right amount of challenge"). We seek to retain and further test the other two absorption items since they had strong loadings across both activities and performed well in all metrics in one of the activities.

\section{Study $1 \mathrm{~b}$-refining the dimensions of flow}

Study $1 \mathrm{~b}$ was designed with the aim of further refining the dimensions of flow. All fluency-related items from Study 1a were retained because they successfully captured the core element of fluency (i.e., things going well). However, it was necessary to add new absorption items that correspond to the underlying attention-based process (Dietrich, 2004). Four new items were developed for the absorption dimension to ensure that each dimension was assessed using an equal number of items (six).

The developed items were consistent with the findings of Study 1a, which revealed that the second dimension of flow and its characteristic experiences result from concentrating on something for an extended period of time (Dietrich, 2004). To choose the experiences that would exemplify this underlying process, we used characteristic flow experiences (i.e., the loss of self-consciousness and the merging of action and awareness) that are predicated on focusing one's full attention on something for a prolonged period of time (Csikszentmihalyi, 1975; Dietrich, 2003). As a result, the following items we developed for the music task in this pretest: "The song was the only thing on my mind," "I felt like it was just me and the song," "I was one with the song," and "I was unaware of anything else."

\section{Participants and procedure}

The sample for this study consisted of 419 TurkPrime panelists $\left(M_{\text {age }}=45.00, S D=16.50,38.7 \%\right.$ male $)$. Given the consistency in dimensionality across the performanceoriented (Sudoku) and experiential (music) tasks in Study 1a, the participants performed the same experiential music task as in Study 1a, and then completed the new flow measures. In this study, sample size was determined according to 
Jackson's (2003) 20:1 rule (20 participants per parameter), which helps to reduce error and increase power. Since 21 parameters were estimated in Study 1b, the ideal sample size was set at 420 participants.

\section{Statistical analysis}

We explored the dimensions of flow using the same procedure as in Study 1a.

\section{Results}

The eigenvalues over one rule, scree tests, and parallel analysis once again revealed two dimensions of flow: fluency and absorption (see Table 2 for the new items and their factor loadings). Absorption explained $47.4 \%$ of the variance, while fluency explained $10.5 \%$. To further refine the two dimensions, we used the same criteria as in the first pretest to eliminate experiences that make small contributions (i.e., communality below .40) and overlap with other experiences (i.e., cross-loadings exceeding 0.32). Specifically, three absorption items and three fluency items were withdrawn, leaving a six item measure of flow, with three items capturing each dimension (see Table 2). These changes enhanced the clarity of the two dimensions, as the remaining items did a good job of capturing both dimensions of flow and explaining a substantial portion of the variance in flow.

\section{Discussion}

The results of Study $1 \mathrm{~b}$ provide additional support for the two-dimensional conceptualization of flow and the processes which underlie its dimensions. The flow experiences loaded on their predicted dimensions, and the refined items helped to explain the absorption dimension; these results indicate that we have successfully captured the essence of both dimensions. The results of Study $1 \mathrm{~b}$ also yielded a new measure of flow, which we have named the Two-Dimensional Flow Scale (TDFS).

\section{Study 2}

The results of Studies 1a and 1b supported a two-dimensional view of flow. In Study 2, we seek to test Hypothesis 1 by using a performance-oriented task to confirm the twodimensional structure of flow.

\section{Participants and procedure}

The sample for Study 2 consisted of 186 MTurk workers $\left(M_{\text {age }}=43.84, S D=15.42,37.1 \%\right.$ male $)$. Sample size was determined based on Wolf et al.'s (2013) recommendation that studies using models with two factors and three indicators per factor employ samples of at least 180 participants. In this study, participants were instructed to play an online version of Pacman for approximately $5 \mathrm{~min}$, and then to
Table 2 Study $1 \mathrm{~b}$ factor loadings

\begin{tabular}{|c|c|c|c|c|c|c|}
\hline \multirow[t]{2}{*}{ Items } & \multicolumn{3}{|c|}{ Initial factor solution } & \multicolumn{3}{|c|}{ Final factor solution } \\
\hline & $\overline{\mathrm{A}}$ & $\mathrm{F}$ & $\mathrm{h}^{2}$ & $\overline{\mathrm{A}}$ & $\mathrm{F}$ & $\mathrm{h}^{2}$ \\
\hline $\mathrm{F}_{1}$. My thoughts ran fluidly and smoothly & & .69 & .63 & & .56 & .55 \\
\hline $\mathrm{F}_{2}$. I had no difficulty concentrating ${ }^{\mathrm{a}}$ & & .53 & .35 & & & \\
\hline $\mathrm{F}_{3}$. My mind was clear ${ }^{\mathrm{a}}$ & & .69 & .61 & & & \\
\hline $\begin{array}{l}\mathrm{F}_{4} \text {. My thoughts seemed to happen naturally and } \\
\text { on their own }\end{array}$ & & .59 & .52 & & & \\
\hline $\mathrm{F}_{5}$. I knew what I was doing each step of the way & & .81 & .47 & & .73 & .50 \\
\hline $\mathrm{F}_{6}$. I felt that I had everything under control & & .83 & .59 & & .82 & .66 \\
\hline$A_{1} . I$ lost track of time & .85 & & .58 & .79 & & .54 \\
\hline $\mathrm{A}_{2}$. I was completely lost in thought ${ }^{\mathrm{a}}$ & .72 & & .44 & & & \\
\hline $\mathrm{A}_{3}$. The song was the only thing on my mind ${ }^{\mathrm{a}}$ & .69 & & .63 & & & \\
\hline $\mathrm{A}_{4}$. I felt like it was just me and the song & .85 & & .77 & .82 & & .72 \\
\hline $\mathrm{A}_{5}$. I was one with the song ${ }^{\mathrm{a}}$ & .85 & & .75 & & & \\
\hline $\mathrm{A}_{6}$. I was unaware of anything else & .74 & & .61 & .79 & & .65 \\
\hline$\%$ of variance & $47.4 \%$ & $10.5 \%$ & $57.9 \%$ & $46.2 \%$ & $14.2 \%$ & $60.4 \%$ \\
\hline
\end{tabular}

All extraction communality coefficients are greater than initial communality coefficient; loadings less than .32 are not shown

$A$ absorption, $F$ fluency, $h^{2}$ communality coefficient after extraction

${ }^{a}$ Items eliminated from further analysis 
complete the TDFS and some demographic questions related to age and gender.

\section{Statistical analysis}

The two-dimensional structure of flow was confirmed via confirmatory factor analysis (CFA) with IBM SPSS Amos 22. This analysis comprised a comparison of two models: the unidimensional model, wherein all indicators load directly onto the latent flow factor; and the two-dimensional model, wherein flow is a higher-order factor and fluency and absorption are first-order factors. The following three items were used to assess fluency: "My thoughts ran fluidly and smoothly," "I knew what I was doing each step of the way," and "I felt that I had everything under control." In contrast, the following three items were used to assess absorption: "I lost track of time," "I felt like it was just me and the game," and "I was unaware of anything else."

\section{Results}

The comparison of the single-factor model (all items loading on the latent flow factor) and the higher-order two-factor model (absorption and fluency items loading on their respective factors with flow as a second-order latent factor) revealed that the two-factor model had better fit statistics, and that these statistics were also satisfactory (i.e., $\mathrm{CFI} / \mathrm{TLI} \geq .95$, RMSEA $\leq .06, \mathrm{SRMR} \leq .03$ (Hu \& Bentler, 1999; Brown, 2006)). The fit statistics for both models are presented in Table 3. These results further demonstrate that flow is comprised of two distinct but related dimensions, thus supporting Hypothesis 1.

\section{Discussion}

The results of Study 2 confirm that flow is characterized by two aspects-fluency and absorption-and further support the suitability of the two-dimensional conceptualization over the unidimensional conceptualization. Given these results, it is important to demonstrate the discriminant and convergent validity of the TDFS. This is the objective of Study 3.

\section{Study 3}

Study 3 had two primary goals. First, we sought to demonstrate the relationship between the two dimensions and three existing scales of flow: the Core Flow scale (Martin \& Jackson, 2008), the MJ-FSS (Martin \& Jackson, 2008), and the flow questionnaire, which focuses on the absorption-related experiences of flow (Csikszentmihalyi \& Csikszentmihalyi, 1988). Our second goal in Study 3 was to demonstrate that both dimensions are related to characteristic variable of flow, and different from those that are inconsistent with it. The concept of mindfulness provides an interesting opportunity for juxtaposition, as some aspects of it are concordant with flow, while others are discordant. As such, we measured aspects of mindfulness that are consistent with flow (i.e., openness and de-centering), as well as positive affect for convergent validity. In addition, we also measured aspects of mindfulness that have been shown to be inconsistent with flow (i.e., self-reflective awareness and situational awareness; Sheldon et al., 2015).

People experiencing flow have been suggested to have heightened awareness (Csikszentmihalyi \& Lefevre, 1989). However, since attention is a limited resource, it is not possible for them to have a heightened awareness of everything around them. Flow is associated with a heightened awareness of task-related stimuli and, as a result, a decreased awareness of everything else, including perceptions of the self (Csikszentmihalyi, 1975). Indeed, findings have demonstrated a negative relationship between flow and the selfreflective aspect of mindfulness (Sheldon et al., 2015), and that the processing of higher-order constructs, such as the "self," is thwarted during flow (Dietrich, 2004). We measure the self-reflective awareness aspect of mindfulness in order to assess discriminant validity.

On the other hand, the de-centering and openness aspects of mindfulness should be related to both dimensions of flow. De-centering refers to a shift away from personal identification with thoughts and feelings (Teasdale et al., 2002), which should allow one to experience the present moment without ruminating or reflecting on it, thereby enhancing one's ability to become absorbed in a task and to experience it fluently due to a decrease in unnecessary thoughts. Openness should
Table 3 Study 2 goodness-of-fit indicators of models for flow dimensions

\begin{tabular}{lllllll}
\hline Model & $\chi^{2}(\mathrm{p})$ & $\mathrm{df}$ & CFI & TLI & RMSEA & SRMR \\
\hline Single-factor & $259.29(.000)$ & 9 & .58 & .30 & .39 & .18 \\
Two-order & $13.8(.087)$ & 8 & .99 & .98 & .06 & .03 \\
\hline
\end{tabular}

The fit statistics are for the single-factor model (all items loading on the latent flow factor) and the twofactor model (absorption and fluency items loading on their respective factors with flow as a second-order latent factor)

$d f$ degrees of freedom, CFI comparative fit index, TLI Tucker-Lewis index, RMSEA root mean square error of approximation, SRMR standardized root mean square residual 
have a similar effect on flow, as it represents experiential receptivity to information and stimuli and a willingness to have new experiences (Lau et al., 2006; McCrae \& Costa, 1985), thus facilitating one's attention and absorption into a task without the burden of ruminative thought or worry. Lastly, since flow is also inherently enjoyable, we measured positive affect, which should converge with both dimensions.

\section{Participants and procedure}

The participants (449 Mturk workers, $M_{\text {age }}=47.87$, $S D=15.91$, and $36.8 \%$ male) engaged in the same music experience as in the prior studies. Of the original 520 participants, 71 were removed due to failing the attention check, which was performed by embedding the item, "I often eat cement," in one of the scales. If participants answered anything other than 1 (not at all) on a 1-7 scale, they were removed (Huang et al., 2015). A sensitivity power analysis using R package "pwr" (alpha $=.05$, two-tailed, beta $=.80$ ) revealed that 781 participants would be required to detect a weak correlation $(r=.10)$, while 85 would be required to detect a medium size correlation $(r=.30)$. Our correlation analysis had $80 \%$ power to detect a correlation coefficient of $r=.13$ (weak correlation).

\section{Measures}

Flow was measured using the TDFS developed in Study 1a, Study 1b, and Study 2, which includes six items: three for absorption $(\alpha=.85)$ and three for fluency $(\alpha=.85)$. After eliminating two areas of localized strain (as indicated by modification indices), the fit statistics for the six-item TDFS were as follows: $\mathrm{CMIN}(\mathrm{p})=8.0(.235), \mathrm{df}=6, \mathrm{CFI}=.99$, $\mathrm{TLI}=.99$, RMSEA $=.03$, SRMR $=.02$. These fit statistics were satisfactory [i.e., CFI/TLI $\geq .95$, RMSEA $\leq .06$, SRMR $\leq .03$ (Brown, 2006; Hu \& Bentler, 1999)]. We also captured other measures of flow, including the Core Flow
Scale (Martin \& Jackson, 2008; $\alpha=.86$ ), the MJ-FSS (Martin \& Jackson, 2008; $\alpha=.88)$, and the flow questionnaire (quote) measure (Csikszentmihalyi \& Csikszentmihalyi, 1988) (“yes": 177 participants (39.4\%) vs. "no": 272 participants (60.6\%)).

For discriminant validity, self-awareness $(\alpha=.86)$ was measured using 3 items from the situational self-awareness scale (Govern \& Marsch, 2001). For convergent validity, we measured the de-centering ( 3 items, $\alpha=.76$ ) and openness ( 4 items, $\alpha=.82$ ) dimensions of mindfulness using the Toronto Mindfulness Scale (Lau et al., 2006). Positive affect was measured using the 10 positive-valence items from the PANAS ( $\alpha=.95$, Watson et al., 1988). It is also worth noting that some measures were included for exploratory purposes in this and other studies and are not included in the analysis. Please see the Supplementary Appendix for a full description of the measures used in this analysis.

\section{Statistical analysis}

We computed correlations between the dimensions of flow, other flow measures, and similar/dissimilar concepts in order to examine how they relate to one another. We expected the correlations to be moderate (.30 to .49) or strong (above .5) for convergent validity and weak (below .3) for discriminant validity (Campbell \& Fiske, 1959; Cohen, 1988; Furr, 2017).

\section{Results}

Descriptive statistics and correlations are presented in Table 4. First, we evaluated the discriminant validity of the TDFS by examining the correlations between its two dimensions and self-awareness. Fluency and absorption were strongly related to each and were both found to be weakly correlated to self-awareness. Together, these results support the discriminant validity of the TDFS and its dimensions,
Table 4 Study 3 descriptive statistics and correlations

\begin{tabular}{lllllllllllll}
\hline & $M$ & $S D$ & 1 & 2 & 3 & 4 & 5 & 6 & 7 & 8 & 9 \\
\hline 1 & Flow (fluency) & 4.6 & 1.7 & .85 & & & & & & & & \\
2 & Flow (absorption) & 3.4 & 1.8 & $.59^{*}$ & .85 & & & & & & & \\
3 & Core flow scale & 2.9 & 1.2 & $.67^{*}$ & $.81^{*}$ & 86 & & & & & & \\
4 & MJ-FSS & 4.2 & 1.5 & $.71^{*}$ & $.68^{*}$ & $.81^{*}$ & .88 & & & & & \\
5 & Flow questionnaire & 0.4 & 0.5 & $.38^{*}$ & $.62^{*}$ & $.63^{*}$ & $.53^{*}$ & - & & & & \\
6 & Self-awareness & 1.9 & 1.3 & .08 & $.25^{*}$ & $.25^{*}$ & $.21^{*}$ & $.16^{*}$ & .86 & & & \\
7 & Decentering & 2.6 & 1.1 & $.54^{*}$ & $.64^{*}$ & $.68^{*}$ & $.68^{*}$ & $.53^{*}$ & $.32^{*}$ & .76 & & \\
8 & Openness & 2.5 & 1.1 & $.45^{*}$ & $.57^{*}$ & $.61^{*}$ & $.64^{*}$ & $.47^{*}$ & $.31^{*}$ & $.72^{*}$ & .82 & \\
9 & Positive affect & 3.1 & 1.1 & $.62^{*}$ & $.66^{*}$ & $.78^{*}$ & $.76^{*}$ & $.52^{*}$ & $.21^{*}$ & $.66^{*}$ & $.62^{*}$ & .95 \\
\hline
\end{tabular}

Internal reliability coefficients are on the diagonal MJ-FSS Martin and Jackson (2008) flow short scale $* p<.05, * * p<.01$ 
indicating that there is little to no overlap between the measures.

Next, we assessed the convergent validity of the TDFS by examining its associations with similar variables and other flow scales. Our findings revealed that fluency was strongly correlated with de-centering and positive affect, and moderately correlated with openness, while absorption was found to be strongly correlated with decentering, openness, and positive affect. Overall, the variables that were expected to be associated with fluency and absorption were strongly correlated with both dimensions (with the exception of openness, which was close to the cutoff value for a "strong" correlation), thus supporting the convergent validity of the TDFS.

Lastly, as expected, both dimensions correlated strongly with existing flow scales. Interestingly, fluency had a stronger correlation with the Core Flow scale compared to the absorption dimension, while both dimensions correlated equally strongly with the MJ-FSS. Furthermore, a moderate correlation was observed between fluency and the Flow questionnaire (quote) measure, while a strong correlation was observed between absorption and the questionnaire. These findings make sense when considering the quotes in the flow questionnaire, as those used to characterize flow tend to focus on its absorption-related experiences. Overall, the correlation between the TDFS and other similar measures once again indicates that it possesses sufficient convergent validity. The one exception to these findings is the correlation between fluency and the Flow questionnaire (quote) measure, which was much weaker than all other correlations. This result was expected, as the quotes used in the flow questionnaire focus on the absorption-related experiences of flow.

\section{Discussion}

The results of Study 3 indicate that the proposed flow dimensions are related to the expected constructs, yet do not overlap with alternative variables. This supports the discriminant and convergent validity of the TDFS. Given these findings, we explore the relationships between fluency, absorption, and various antecedents and consequences in Studies 4 and 5. This inquiry is important from a theoretical standpoint, as it is critical to understand whether nuanced relationships exist between the dimensions of flow and other variables.

\section{Study 4}

The primary goal of Study 4 was to test the relationships between the two dimensions of flow and antecedents/consequences (Hypotheses 2a, 2b, 2c, 3a, and 3b). In addition, we also sought to compare our two-dimensional conceptualization with the unidimensional conceptualization (i.e., MJ-FSS) with respect to these relationships (Martin \& Jackson, 2008). Finally, we aimed to provide additional support for the fluency dimension being characterized as a general perception of fluency that is rooted in both fluent thought and fluent action. To support the underlying importance of fluent thought we seek to demonstrate a strong relationship between familiarity and the fluency dimension (Hypothesis 2a), since familiarity and processing fluency are tightly linked (Song \& Schwarz, 2009). To support the underlying importance of fluent action we also seek to demonstrate strong relationships between skills, progress, and the fluency dimension (Hypotheses 2b, 2c).

\section{Participants and procedure}

The initial sample for Study 4 consisted of 359 MTurk workers; however, 21 were omitted from the final sample due to failing the attention check, which was implemented by embedding the item, "I often eat cement," in one of our scales. Thus, the final sample contained 338 participants $\left(M_{\text {age }}=36.23, S D=10.12,55.8 \%\right.$ male $)$. For this study, the participants were instructed to play a version of the Bejeweled video game until they received a "game-over" message. Prior to performing the task, they were provided with a short tutorial on how to play the game, which included text descriptions, visuals, and a live demonstration. When the game was finished, the participants were asked to complete the measures of flow, measures of the predicted antecedent and outcome variables, and demographic questions.

A sensitivity power analysis using R package "pwr" (alpha $=.05$, two-tailed, beta $=.80)$ indicated that a sample of 781 observations would be required to detect a weak correlation $(r=.10)$, while a sample of 85 observations would be necessary to detect a medium-size correlation $(r=.30)$. Our correlation analysis had $80 \%$ power to detect a correlation coefficient of $r=.15$ (weak correlation). The regression analyses with flow as an antecedent had $80 \%$ power to detect effect size with $f^{2}=.04$ (small effect size; for a regression with 5 independent variables and 338 participants) and $f^{2}=.03$ (small effect size; for a regression with 4 independent variables and 338 participants). The regression analyses with flow as an outcome had $80 \%$ power to detect effect size with $f^{2}=.02$ (small effect size; for regressions with 1 independent variable and 338 participants).

\section{Measures}

Fluency $(\alpha=.89)$ and absorption $(\alpha=.90)$ were measured using the proposed TDFS. The two-dimensional structure was confirmed using the same procedure as in previous studies, with results indicating satisfactory fit statistics $(\mathrm{CMIN}(\mathrm{p})=15.70(.047), \mathrm{df}=8, \mathrm{CFI}=.99, \mathrm{TLI}=.99$, 
RMSEA $=.05$, SRMR $=.03$ ). The MJ-FSS was also measured using the same procedure as in previous studies $(\alpha=.81)$.

Familiarity with a task and an appropriate level of skill have been suggested as being critical antecedents to entering flow in performance-oriented tasks (Keller et al., 2011a, 2011b). We assessed familiarity with Bejeweled by asking participants, "how familiar are you with the strategies/rules of Bejeweled?" (1=not at all, $7=$ very familiar), while skill was assessed with the item, "how skilled were you at Bejeweled before playing today?" $(1=$ not at all skilled, $7=$ very skilled). Progress was measured based on the number of gems cleared per minute, which was tracked by the game software, reported on the final screen, and recorded by the research assistant running the study.

With regards to consequences, flow has been suggested to give rise to feelings of presence (Sheldon et al., 2015) and an increased desire to engage in the task that elicited flow again in the future (Martin \& Jackson, 2008). Presence was measured using the scale developed by Kim and Biocca (1997; $\alpha=.95$ ), and engagement intentions were assessed using the question, "how likely would you be to play Bejeweled again in the next week?" ( $1=$ not at all likely, $7=$ very likely). See the Supplementary Appendix for a full description of the measures.

\section{Statistical analysis}

Hierarchical regression analysis was employed both to evaluate the relationships between the TDFS and the suggested consequences-presence and intentions to play again-and to compare its predictive power against the MJ-FSS scale. In the first step, we controlled for the effects of age, familiarity, and skill; in the second step, we entered the MJ-FSS score; and in the third step, we entered fluency and absorption as measured using the TDFS. A similar approach was employed to evaluate the antecedents to the TDFS, with game progress being entered in the first step, familiarity being entered in the second step, and skill being entered in the third step.

\section{Results}

Descriptive statistics and correlations are presented in Table 5. Fluency has weak positive correlations with absorption and presence, moderate positive correlations with intention to play the game again, progress made in the game, familiarity, and skill, and a strong positive correlation with the MJ-FSS. Absorption had a strong positive correlation to the MJ-FSS and presence, and a moderate positive correlation to intention to play again. Absorption was not significantly related to progress in the game, familiarity, or skill. All correlations are in the expected directions.

The results of the regression analysis of flow outcomes (see Table 6) indicate that the two dimensions are related to outcomes, such as presence and intention to play again, in different ways. Fluency was weakly and negatively related to presence $(\beta=-.14, p<.05)$ and not related to intention to play again $(\beta=.03$, n.s.). Absorption was strongly positively related to presence $(\beta=.64, \mathrm{p}<.001)$ and moderately positively related to intention to play again $(\beta=.32, \mathrm{p}<.001)$. Compared to the MJ-FSS, the TDFS explained nearly twice as much variance in presence (an additional $31 \%$ after controlling for the MJ-FSS), and slightly more variance in intentions to play again (an additional 7\% after controlling for the MJ-FSS).

The results of the regression analysis for flow antecedents (see Table 7) indicated that progress in the game was not related to either of the flow dimensions, and that familiarity $(\beta=.20, p<.01)$ and skill $(\beta=.33, p<.001)$ were only related to fluency. Familiarity and skill explained a total of $27 \%$ of the variance in flow.
Table 5 Study 4 descriptive statistics and correlations

\begin{tabular}{|c|c|c|c|c|c|c|c|c|c|c|c|}
\hline & & $M$ & $S D$ & 1 & 2 & 3 & 4 & 5 & 6 & 7 & 8 \\
\hline 1 & Fluency & 5.0 & 1.5 & .89 & & & & & & & \\
\hline 2 & Absorption & 4.6 & 1.8 & $.18 * *$ & .90 & & & & & & \\
\hline 3 & MJ-FSS & 4.9 & 1.0 & $.69 * *$ & $.53 * *$ & .81 & & & & & \\
\hline 4 & Presence & 3.6 & 1.8 & $.19^{* *}$ & $.74 * *$ & $.52 * *$ & .95 & & & & \\
\hline 5 & Intention to play again & 3.5 & 2.1 & $.27 * *$ & $.44 * *$ & $.43 * *$ & $.50 * *$ & - & & & \\
\hline 6 & $\begin{array}{l}\text { Progress (jewels } \\
\text { cleared per minute) }\end{array}$ & 52.0 & 25.2 & $.29 * *$ & .09 & $.28 * *$ & .01 & $.41 * *$ & - & & \\
\hline 7 & Familiarity & 4.7 & 2.0 & $.46^{* *}$ & .09 & $.42 * *$ & .10 & $.23 * *$ & $.43 * *$ & - & \\
\hline 8 & Skill & 3.5 & 1.7 & $.49 * *$ & .04 & $.39 * *$ & $.13 *$ & $.22 * *$ & $.40 * *$ & $.73 * *$ & - \\
\hline
\end{tabular}


Table 6 Study 4 hierarchical regression analysis for flow outcomes

\begin{tabular}{|c|c|c|c|c|c|c|}
\hline \multirow[t]{2}{*}{ Predictors } & \multicolumn{6}{|c|}{ Standardized regression coefficients } \\
\hline & Presence & & & Intention & & \\
\hline Age & .05 & -.01 & -.06 & .08 & .04 & .02 \\
\hline Familiarity & .02 & $-.15^{*}$ & $-.12 *$ & .09 & -.03 & -.02 \\
\hline Skill & .12 & .01 & $.14 * *$ & .15 & .07 & .12 \\
\hline MJ-FSS & & $.59 * * *$ & $.28 * * *$ & & $.41 * * *$ & $.19^{*}$ \\
\hline Fluency & & & $-.14 *$ & & & .03 \\
\hline Absorption & & & $.64 * * *$ & & & $.32 * * *$ \\
\hline $\mathrm{F}$ & 2.11 & 34.38 & 81.39 & 6.03 & 18.77 & 18.60 \\
\hline $\mathrm{R}^{2}$ & .02 & $.29 * * *$ & $.60^{* * *}$ & $.05^{* * *}$ & $.18 * * *$ & $.25 * * *$ \\
\hline$\Delta \mathrm{R}^{2}$ & & $.27 * * *$ & $.31 * * *$ & & $.13 * * *$ & $.07 * * *$ \\
\hline
\end{tabular}

**MJ-FSS Flow Short Scale by Martin and Jackson (2008)

${ }^{*} p<.05, * * p<.01, * * * p<.001$

\begin{tabular}{|c|c|c|c|c|c|c|}
\hline \multirow{3}{*}{$\begin{array}{l}\text { Predictors } \\
\text { Progress }\end{array}$} & \multicolumn{6}{|c|}{ Standardized regression coefficients } \\
\hline & \multicolumn{3}{|l|}{ Fluency } & \multicolumn{3}{|c|}{ Absorption } \\
\hline & $.29 * * *$ & $.11 *$ & .07 & .08 & .06 & .06 \\
\hline Familiarity & & $.42 * * *$ & $.20 * *$ & & .07 & .11 \\
\hline Skill & & & $.33 * * *$ & & & -.07 \\
\hline $\mathrm{F}$ & 30.96 & 49.28 & 42.89 & 2.31 & 1.72 & 1.41 \\
\hline $\mathrm{R}^{2}$ & $.09 * * *$ & $.23 * * *$ & $.27 * * *$ & .01 & .01 & .01 \\
\hline$\Delta \mathrm{R}^{2}$ & & $.14 * * *$ & $.05 * * *$ & 2.31 & .00 & .00 \\
\hline
\end{tabular}

Table 7 Study 4 hierarchical regression analysis for flow antecedents context to further explore the roles of familiarity, skill, and progress in eliciting flow.

\section{Study 5}

Study 5 had two primary goals. First, we sought to replicate the nuanced relationships between the dimensions of flow and its antecedents and consequences in a new context, as we wanted to be certain that the differences in the investigated relationships were not a product of the specific task in Study 4. The second goal of Study 5 was to gain further insight into the process through which flow happens given Study 4's finding that antecedents were strongly associated with fluency, but not with absorption. This finding hints at a potential process wherein the fluency dimension is critical to experiencing absorption, which is consistent with the findings of nascent research suggesting that absorption possesses an emergent, time-based element (Lavoie \& Main, 2019a).

We posit that skill is an important antecedent to flow because it gives rise to fluent action, as captured by the fluency dimension, which allows one to maintain focus on the task for long enough to become absorbed. This is important to note, as skill should not elicit absorption directly; rather, it should only do so indirectly through the fluency 
dimension. We test this potential process of entering flow and hypothesize that fluency-related experiences will play an important role in the emergence of absorption related experiences. Stated formally,

Hypothesis 4: Fluency will mediate the relationship between skill and absorption.

\section{Participants and procedure}

The sample for this study was comprised of 256 undergraduate students $\left(M_{\text {age }}=19.91, S D=5.67,59.8 \%\right.$ male $)$. Study 5 employed the same procedure as Study 4, only this time the participants were instructed to play an online version of the video game, Tetris, instead of Bejeweled. As in Study 4, participants were given a short tutorial of how to play, including a text description of the game. After receiving the "game over" notification, the participants were asked to complete the TDFS, measures of antecedent and consequence variables and demographic questions.

A sensitivity power analysis using $\mathrm{R}$ package "pwr" (alpha $=.05$, two-tailed, beta $=.80)$ indicated that a sample size of 134 observations would be required to detect a weak correlation $(r=.10)$, while 49 observations would be required to detect a medium-size correlation $(r=.30)$. Our correlation analysis had $80 \%$ power to detect a correlation coefficient of $r=.18$ (weak correlation). The regression analyses with flow dimensions as an antecedent had $80 \%$ power to detect effect size with $f^{2}=.05$ (small effect size; for a regression with 5 independent variables and 248 participants). The regression analyses with flow as an outcome also had $80 \%$ power to detect effect size with $f^{2}=.05$ (small effect size; for regressions with 3 independent variables and 246 participants).

\section{Measures}

The fluency $(\alpha=.93)$ and absorption $(\alpha=.89)$ dimensions were measured using the proposed TDFS. The two-dimensional structure was confirmed using the same procedure as in previous, with results showing satisfactory fit statistics $(\mathrm{CMIN}(\mathrm{p})=16.417(.022), \mathrm{df}=7, \mathrm{CFI}=.99, \mathrm{TLI}=.98$, RMSEA $=.07$, SRMR $=.02$ ).

The antecedents were measured using the same approach as Study 4: skill was assessed using the question, "how skilled were you at Tetris before playing today?" $(1=$ not at all skilled, $7=$ very skilled), and familiarity was measured by asking, "how familiar are you with the strategies/ rules of Tetris?" ( $1=$ not at all, $7=$ very familiar $)$. We also used a progress measure that asked the participants what level they had reached in Tetris; this measure consisted of an open-ended question that allowed the participants to enter a number directly. Consequences were measured using the same method as in Study 4: presence was assessed using 5 items ( $\alpha=.96$; Kim \& Biocca, 1997), and engagement intentions were measured by asking "how likely would you be to play Tetris again in the next week?" $(1=$ not at all likely, $7=$ very likely).

\section{Results}

Descriptive statistics and correlations are presented in Table 8 . As can be seen, fluency was strongly and positively correlated with absorption, moderately and positively correlated with skill, presence, and progress, and weakly and positively correlated with familiarity and intention to play again.

The results of the regression analysis of flow outcomes (see Table 9) replicated those of Study 4, with only absorption being related to presence and intention to play again. Specifically, participants who reported higher levels of absorption also reported a greater sense of presence $(\beta=.59$, $\mathrm{p}<.001)$ and stronger intentions to play the game again $(\beta=.17, p<.05)$. These effects were observed beyond the effects of familiarity and skillfulness, explaining $35 \%$ of the variance in presence and $18 \%$ of the variance in intention to play again.

The results of the regression analysis of flow antecedents (see Table 10) showed a positive relationship between skill and with fluency $(\beta=.23, \mathrm{p}<.01)$. As we hypothesized,

Table 8 Study 5 correlations

\begin{tabular}{|c|c|c|c|c|c|c|c|c|}
\hline & & 1 & 2 & 3 & 4 & 5 & 6 & 7 \\
\hline 1 & Fluency & .93 & & & & & & \\
\hline 2 & Absorption & $.59 * *$ & .89 & & & & & \\
\hline 3 & Familiarity & $.28 * *$ & .06 & - & & & & \\
\hline 4 & Skill & $.37 * *$ & $.14^{*}$ & $.61 * *$ & - & & & \\
\hline 5 & Presence & $.35 * *$ & $.57 * *$ & $.16^{* *}$ & $.27 * *$ & .96 & & \\
\hline 6 & Intention to play again & $.27 * *$ & $.23 * *$ & $.34 * *$ & $.28 * *$ & $.31 * *$ & - & \\
\hline 7 & Progress & $.36 * *$ & $.21 * *$ & $.17 * *$ & $.32 * *$ & $.19 * *$ & $.15^{*}$ & - \\
\hline
\end{tabular}

**Internal reliability coefficients are on the diagonal

$* p<.05, * * p<.01$ 
Table 9 Study 5 hierarchical regression analysis for flow outcomes

\begin{tabular}{|c|c|c|c|c|}
\hline & Standardi & regression & fficients & \\
\hline & Presence & & Intention & \\
\hline Age & .10 & .05 & -.10 & $-.13 *$ \\
\hline Familiarity & .00 & .02 & $.27 * * *$ & $.26 * * *$ \\
\hline Skill & $.24 * * *$ & $.20 * * *$ & .15 & .10 \\
\hline Fluency & & -.09 & & .09 \\
\hline Absorption & & $.59 * * *$ & & $.17 *$ \\
\hline $\mathrm{F}$ & 6.70 & 27.58 & 13.39 & 11.59 \\
\hline $\mathrm{R}^{2}$ & $.07 * * *$ & $.35^{* * *}$ & $.13^{* * *}$ & $.18 * * *$ \\
\hline$\Delta \mathrm{R}^{2}$ & & $.28 * * *$ & & $.05 * * *$ \\
\hline
\end{tabular}

$* p<.05, * * p<.01, * * * p<.001$

progress was positively related to both fluency $(\beta=.27$, $\mathrm{p}<.01)$ and absorption $(\beta=.18, \mathrm{p}<.01)$, though its relationship with fluency was stronger. Familiarity was not related to either dimension in this study. These variables explained a total of $20 \%$ of the variance in fluency and $5 \%$ of the variance in absorption.

Although no relationship was observed between skill and the absorption dimension of flow, we suggest that they will be indirectly related due to skill's ability to facilitate the fluency dimension of flow. In order to support this relationship, we ran a mediation model with the fluency dimension mediating the relationship between skill and absorption using Model 4 of the PROCESS macro in SPSS (Hayes, 2018). As expected, the results revealed that the fluency dimension mediated the absorption dimension. Specifically, a significant indirect effect was observed [conditional effect $=.21, \mathrm{SE}=.04,95 \% \mathrm{CI}: .14, .29$ ], such that increases in skill resulted in increased fluency [conditional effect $=.34$, $\mathrm{SE}=.05,95 \% \mathrm{CI}: .23, .45]$, which in turn mediated the absorption dimension of flow [conditional effect $=.63$, $\mathrm{SE}=.06,95 \%$ CI: .52, .74].

\section{Discussion}

The results of Study 5 provide further support for the assumption that nuanced relationships exist between the two flow dimensions and other variables. As in Study 4, the antecedents of flow (i.e., skill and familiarity) had significant positive relationships with its fluency dimension. Furthermore, the results related to the consequences of flow also aligned with those of Study 4, as significant relationships were observed between the established consequences of flow (i.e., presence and engagement intentions) and the absorption dimension, while only weak or non-significant relationships were observed with the fluency dimension. Moreover, the findings further elucidated the nature of the fluency dimension by foregrounding the importance of fluent action, as skills and progress were significantly related to the fluency dimension.

The results of Study 5 also provide insight into flow's underlying processes. In particular, the mediation results confirm that absorption is an emergent state that is made possible by progress in a task, which is captured by the fluency dimension of flow. Skill, an established antecedent of flow, directly enhances the fluency dimension, but is only indirectly associated with the absorption dimension via the fluency dimension. Interestingly, the correlation between the fluency and absorption dimensions was much stronger in this study (.59) than in Study 4 (.18). Given that the greater variety of potential actions in Tetris makes it more difficult than Bejeweled (the flow-inducing task in Study 4), it is possible that the dimensions of flow converge during tasks that are more challenging, and thus closer to deepflow.

\section{General discussion}

The results of this research advance the conceptualization of flow in several ways. First, they clarify the dimensionality of flow, providing evidence of a two-dimensional conceptualization comprised of "fluency" and "absorption" dimensions. This research also helps to clarify the nature of these dimensions. As we have shown, the fluency dimension is associated with fluent thought and fluent action, while the absorption dimension is emergent in nature and driven by sustained attention to the focal activity. Importantly, we demonstrate that the two dimensions
Table 10 Study 5 hierarchical regression analysis for flow antecedents

\begin{tabular}{|c|c|c|c|c|c|c|}
\hline \multirow[b]{3}{*}{ Progress } & \multicolumn{6}{|c|}{ Standardized regression coefficients } \\
\hline & \multicolumn{3}{|l|}{ Fluency } & \multicolumn{3}{|l|}{ Absorption } \\
\hline & $.36 * * *$ & $.32 * * *$ & $.27 * * *$ & $.21 * *$ & $.21 * *$ & $.18 * *$ \\
\hline Familiarity & & $.21 * * *$ & .08 & & .02 & -.03 \\
\hline Skill & & & $.23 * * *$ & & & .10 \\
\hline $\mathrm{F}$ & 36.19 & 25.48 & 20.80 & 11.17 & 5.63 & 4.27 \\
\hline $\mathrm{R}^{2}$ & $.13 * * *$ & $.17 * * *$ & $.20 * * *$ & $.04 * * *$ & $.04 * *$ & $.05 * *$ \\
\hline$\Delta \mathrm{R}^{2}$ & & $.04 * * *$ & $.03 * *$ & & .00 & .01 \\
\hline
\end{tabular}

${ }^{*} p<.05, * * p<.01, * * * p<.001$ 
exist across contexts (i.e., performance-oriented and experiential leisure activities), and have nuanced relationships with antecedents and consequences of flow.

The results of this research not only advance flow theory, but they also serve as a foundation for future research aimed at exploring the nomological network of flow and measuring it more precisely. Lastly, we develop an initial understanding of how the two dimensions relate to each other in the emergence of flow. In particular, our mediation findings suggest that the fluency dimension of flow can mediate the absorption dimension.

Our demonstration of the nuanced relationships between the dimensions of flow and its established antecedents and consequences has several theoretical and empirical implications. First, it illustrates the importance of properly measuring the two dimensions when assessing the relationship between flow and other variables. Our results suggest that treating flow as a unidimensional construct may obfuscate its relationships with other variables. While the antecedents of flow may have a strong relationship with its fluency dimension, thus facilitating it, their weak direct relationship with the absorption dimension may cause the overall relationship to seem weaker.

Notably, we show a nuanced relationship between flow and presence. Given their conceptual similarity, our research contributes to the nascent literature aimed at distinguishing these concepts from one another (e.g., Weibel et al., 2008). Specifically, we demonstrate that the fluency dimension of flow is distinct from presence. Similarly, our findings also help clarify the relationship between flow and mindfulness. While several research efforts and lay thought often conceive of the two concepts as being highly related (e.g., Kee \& Wang, 2008), other studies have shown that they are discordant (Sheldon et al., 2015). Our research suggests that some aspects of mindfulness (i.e., decentering and openness) are important for flow, while others (e.g., self-reflective awareness) can thwart it.

Our results also provide greater clarity regarding the fluency dimension, which is based on a general perception of ease and control, fluent thought, and/or fluent action. While the wording of the fluency items on the TDFS captures both fluent thought and action (e.g., "I knew what I was doing"), our findings reveal that fluent thought is especially important, as it can occur with little-to-no physical action and can give rise to the fluency dimension of flow on its own. Taken alongside evidence from performance domains that fluent thought underlies fluent action (Ilundáin-Agurruza, 2015), our results suggest that fluent thought may be at the core of this dimension. That is, it is unlikely to sustain fluent action without fluent thought, but it is possible to sustain fluent thought without fluent action.
The suggested importance of fluent thought in leisure activities also illuminates the potential relationships between flow and constructs like processing fluency (Reber et al., 1998). Our finding that progress contributes to the fluency dimension of flow also advances current understandings of the relationship between performance and flow, as prior findings have suggested that performance is a consequence of flow (Engeser \& Rheinberg, 2008). However, we highlight the importance of performance in giving rise to flow since it is generally equated with smoothly progressing through a task.

Our mediation findings highlight that the emergence of flow is two-dimensional in nature, which represents a potentially important contribution to facilitating future research on flow. In particular, our demonstration of the mediating roles of fluency and efficiency of progress advances current understandings of how to manipulate flow (Kulkarni et al., 2016). Our process findings suggest that fluency-related experiences (e.g., control, automaticity) could be manipulated to induce flow, as they can give rise to absorptionrelated experiences. The ability to manipulate flow via fluency-related experiences provides a viable alternative to the skills-challenge balance approach, which is currently the only established manipulation of flow (e.g., Keller \& Bless, 2008). As a result, experimental research on flow is limited, especially in contexts that are not traditionally skills-based.

Our two-dimensional conceptualization of flow allows it to be studied and measured in experiences not typically associated with skill and performance. This is important because there is growing evidence of flow in more passive tasks, including those that are more experiential in nature and not typically associated with skill (e.g., Lavoie \& Main, 2019b; Novak et al., 2003). It is possible to experience flow during tasks that do not require physical interaction, as the dimensions of flow (i.e., absorption and fluency) can be elicited through the senses (e.g., seeing and hearing) and subsequent psychological processing alone. For example, one can be fully absorbed and perceive a high level of fluency while reading a book. Similarly, while watching a new movie, one can become absorbed in the content and perceive degrees of progress related to learning and/or satisfying curiosity depending on how the story is structured (Van Laer et al., 2014, 2019). Likewise, our results advance the current conceptualizations of flow by shifting emphasis away from the match between high skill level and high task demands, which is perhaps the most commonly understood characteristic of flow (Csikszentmihalyi, 1975; Keller \& Bless, 2008).

Importantly, our revised conceptualization of flow accounts for the role of matching skills with task demands. Matching skills with task demands is one way to develop high levels of absorption and fluency, but it is not the only way to do so, and it is not a particularly strong measure of either dimension. Removing the focus on skills enables 
the study of flow in contexts not traditionally understood as skill and performance-based, and increases its relevance by broadening our understanding of what could be considered a flow state. For example, scrolling through social media can give rise to a flow state (Hamilton et al., 2016).

Clarifying the dimensionality of flow is also important to ensure that it is measured properly. Our results suggest that it is not possible to adequately measure flow using the common method of assessing certain components (e.g., time distortion and balance of skills with task demands), as these items do not capture both dimensions (e.g. Keller $\&$ Bless, 2008). Therefore, the TDFS developed in this paper represents a significant empirical contribution for future research, as it will enable the accurate measurement of flow in leisure activities.

With regards to the proper measurement of flow, we think it is important to highlight the similarities between the TDFS and the FSS (Rheinberg et al., 2003) to illustrate the novelty of our scale. While we removed the three weakest fluency items from the FSS we retained the three strongest items; thus, the fluency dimension of the TDFS is comprised entirely of items from the FSS. Conversely, the absorption dimension of the TDFS retains one item from the FSS ("I lost track of time"), but replaces the others. Thus, the TDFS retains the strongest fluency experiences from the FSS, while providing a new approach to capturing the absorption dimension.

Lastly, our demonstration of flow's two-dimensional structure raises the question of when we can speak of flow as a specific state. We recommend that terminology remain at the general, unidimensional level when referencing flow, with distinctions between dimensions being reserved for conceptual and measurement purposes. We believe that flow is achieved when a certain degree of absorption and fluency are obtained together. Both absorption and fluency exist on a subjective continuum, with increases or decreases in each bolstering or thwarting flow, respectively. It is important to note that both elements are necessary but not sufficient on their own in order for one to experience flow. For example, one could be fully absorbed in an activity but fail to experience flow due to insufficient fluency.

The TDFS represents an important contribution because it provides a more precise understanding of which dimension of flow is being limited. This information can then be used to provide insight into whether it is necessary to increase fluency or absorption in order to foster flow. We do not think it is appropriate to suggest specific values marking the flow threshold, as we expect this threshold to differ across people and contexts. Thus, future research should explore the various combinations of fluency and absorption with regards to flow thresholds. We discuss the limitations of our research and the additional opportunities for future research next.

\section{Limitations and future research}

Our results have several limitations that could provide opportunities for future research. Mostly notably, although some of the activities used in our studies were more active and performance-focused than others, they were ultimately all leisure-based. This is important because differences have been shown across flow states in leisure and work activities. Most notably, flow states in work activities emerge in the presence of more negative emotional activation/arousal (e.g., feeling stressed, nervous) compared to flow states in leisure activities (Engeser \& Baumann, 2014). The nuanced emotional qualities of work activities, particularly increased levels of negative emotional activation/arousal, may lead to differences in the dimensionality of flow and the process through which it emerges. While we are confident in our findings related to the dimensionality of flow, the TDFS and our conclusions related to the process through which flow emerges are ultimately limited to leisure-based activities; as such, the TDFS should be used appropriately in future research.

Relatedly, the activities that were used in our studies to generate the TDFS limit our ability to assess its superiority over prior measures. Since our comparison of the TDFS and prior measures of flow was limited to leisure activities, future research could test the effectiveness of the two measures across several other contexts, including work activities. In addition to testing the different measures, future research could also explore the dimensionality of flow and the relationships between the dimensions in work activities.

Another limitation of this research is the specificity of the antecedents and consequences that were studied. While our results suggest that antecedents to flow may be more related to the fluency dimension, it is possible that some are more directly related to absorption, such as individual differences in action orientation (Baumann et al., 2016). The roles of emotion and body movement could also prove fruitful for exploring the antecedents of flow given their importance related to absorption (Jantzen et al., 2012; Murphy et al., 2018). Individual differences, which are suggested to give rise to flow and its physiological markers, may also have nuanced relationships with the dimensions of flow (Keller et al., 2011a, 2011b; Peifer et al., 2014; Teng, 2011).

Our results also provide preliminary support for the relationship between the dimensions of flow and lay the groundwork for future research exploring the process through which flow develops based on these two dimensions. We demonstrate one way in which the two sets of experiences that comprise flow are related, but we do not suggest that this is the only way. It is possible that the 
absorption-related experiences of flow could also give rise to and sustain the fluency-related experiences. For example, things more directly related to the absorption dimension, such as focused concentration, could increase perceived fluency from a processing perspective by calming other disruptive processes, such as negative emotions (Dolcos et al., 2020). Future research should explore the role that the absorption-related experiences of flow play in facilitating and sustaining its fluency-related experiences.

The TDFS is further limited in that it is based on selfreporting, which is sometimes difficult or impossible to obtain. A new behavioral measure of flow should be developed so that observers could determine flow in such instances. As discussed earlier, sustained fluent action may be a proxy for fluent thought; thus, the degree to which people make "smooth" progress without errors could be used to capture the fluency dimension. Our findings also suggest that the absorption dimension could be assessed using physical cues related to sustained visual attention and body language.

Given our findings supporting the relationship between the two dimensions in eliciting flow, it will be important to develop alternative methods of manipulating flow. Future research should explore a variety of fluency-related enablers to determine which ones are most effective for manipulating flow in leisure contexts. Exploring the processes through which fluency facilitates absorption will help to advance the emerging literature related to the process of flow (Kawabata \& Mallett, 2011). It would also be worthwhile to explore how the two dimensions are related in sustaining flow. Perhaps the distinctiveness of each dimension may become compromised during sustained deepflow states due to the two dimensions merging and supporting each other as a result of being held for a prolonged period. It is possible that the importance of fluency may have been more pronounced in the leisure studies in this research, and that absorption may play a more critical role in sustaining fluency during deepflow.

Accordingly, future research should also explore the dimensionality of deepflow states, as our research was limited to relatively shorter microflow states. The differences between deepflow and microflow, particularly the time and difficulty components, may lead to different results. Perhaps the unidimensional view of flow is more appropriate for deepflow states, as the experiences of ease and attention, and the relationship between them, becomes symbiotic after concentrating for long enough. This is consistent with the differences in the correlations between the two dimensions across Studies 4 and 5, with the relationship being stronger in Study 5, which utilized a more difficult flow-inducing task. This result makes sense, as concentrating on one task for long enough should increase the ease with which one is able to process related stimuli.
Moreover, the progress made within deepflow states is relatively more important to the person than it would be in microflow states and may have a more direct role in driving absorption. Alternatively, the relationship between the two dimensions of flow was not as unified in the shorter microflow states explored in this research, as it is possible to experience fluency without yet being fully absorbed. In summary, we suggest that exploring the relationship between the dimensions of flow in both deepflow and microflow states would be a fruitful line of inquiry, and that our research provides many avenues to do so, most notably through our two-dimensional conceptualization.

\section{Conclusion}

While previous research has conceptualized flow in various ways, this research reveals that flow in leisure activities is most appropriately conceptualized as consisting of two dimensions: fluency and absorption. In separating flow into these two dimensions, we show that experiences related to absorption play a larger role in driving typical consequences of flow, and that some typical antecedents of flow are more directly related to the fluency dimension. Efforts to measure flow solely based on matching skills and task demands, or those based on variables more associated with the absorption dimension, are problematic, as our research demonstrates that both dimensions are necessary to achieve flow. Finally, the TDFS is best suited for capturing the two dimensions of flow during leisure activities, and should therefore be used in such contexts in future research.

Supplementary Information The online version contains supplementary material available at https://doi.org/10.1007/s11031-021-09911-4.

Open Access This article is licensed under a Creative Commons Attribution 4.0 International License, which permits use, sharing, adaptation, distribution and reproduction in any medium or format, as long as you give appropriate credit to the original author(s) and the source, provide a link to the Creative Commons licence, and indicate if changes were made. The images or other third party material in this article are included in the article's Creative Commons licence, unless indicated otherwise in a credit line to the material. If material is not included in the article's Creative Commons licence and your intended use is not permitted by statutory regulation or exceeds the permitted use, you will need to obtain permission directly from the copyright holder. To view a copy of this licence, visit http://creativecommons.org/licenses/by/4.0/.

\section{References}

Agarwal, R., \& Karahanna, E. (2000). Time flies when you're having fun: Cognitive absorption and beliefs about information 
technology usage. MIS Quarterly. https://doi.org/10.2307/32509 51

Aubé, C., Brunelle, E., \& Rousseau, V. (2014). Flow experience and team performance: The role of team goal commitment and information exchange. Motivation and Emotion, 38(1), 120-130. https://doi.org/10.1007/s11031-013-9365-2

Bandura, A. (1982). Self-efficacy mechanism in human agency. American Psychologist, 37(2), 122. https://doi.org/10.1037/0003-066x. 37.2.122

Banos, R., Botella, C., Garcia-Palacios, A., Villa, H., Perpiñá, C., \& Gallardo, M. (1999). Psychological variables and reality judgment in virtual environments: The roles of absorption and dissociation. CyberPsychology \& Behavior, 2(2), 143-148. https://doi.org/10. 1089/cpb.1999.2.143

Bargh, J. A. (1994). The four horsemen of automaticity: Awareness, intention, efficiency, and control in social cognition. Handbook of Social Cognition, 1, 1-40.

Baumann, N., Lürig, C., \& Engeser, S. (2016). Flow and enjoyment beyond skill-demand balance: The role of game pacing curves and personality. Motivation and Emotion, 40(4), 507-519. https://doi. org/10.1007/s11031-016-9549-7

Baumann, N., \& Scheffer, D. (2010). Seeing and mastering difficulty: The role of affective change in achievement flow. Cognition and Emotion, 24(8), 1304-1328. https://doi.org/10.1080/0269993090 3319911

Baumann, N., \& Scheffer, D. (2011). Seeking flow in the achievement domain: The achievement flow motive behind flow experience. Motivation and Emotion, 35(3), 267-284. https://doi.org/10.1007/ s11031-010-9195-4

Bornstein, R. F., \& D’Agostino, P. R. (1992). Stimulus recognition and the mere exposure effect. Journal of Personality and Social Psychology, 63(4), 545-552. https://doi.org/10.1037/0022-3514. 63.4.545

Brown, T. A. (2006). Confirmatory factor analysis for applied research. Guilford.

Campbell, D. T., \& Fiske, D. W. (1959). Convergent and discriminant validation by the multitrait-multimethod matrix. Psychological Bulletin, 56(2), 81. https://doi.org/10.1037/h0046016

Chambon, V., \& Haggard, P. (2012). Sense of control depends on fluency of action selection, not motor performance. Cognition, 125(3), 441-451. https://doi.org/10.1016/j.cognition.2012.07.011

Christandl, F., Mierke, K., \& Peifer, C. (2018). Time flows: Manipulations of subjective time progression affect recalled flow and performance in a subsequent task. Journal of Experimental Social Psychology, 74, 246-256. https://doi.org/10.1016/j.jesp.2017.09. 015

Cohen, J. (1988). Statistical Power Analysis for the Behavioral Sciences (2nd ed.). Routledge.

Costello, A. B., \& Osborne, J. (2005). Best practices in exploratory factor analysis: Four recommendations for getting the most from your analysis. Practical Assessment, Research, and Evaluation, 10(1), 7.

Csikszentmihalyi, M. (1975/2000). Beyond boredom and anxiety: Experiencing flow in work and play (2nd ed.). Jossey Bass.

Csikszentmihalyi, M., \& Csikszentmihalyi, I. (1988). Optimal experience: Psychological studies of flow in consciousness. Cambridge University Press.

Csikszentmihalyi, M., \& LeFevre, J. (1989). Optimal experience in work and leisure. Journal of Personality and Social Psychology, 56(5), 815. https://doi.org/10.1037/0022-3514.56.5.815

Dietrich, A. (2003). Functional neuroanatomy of altered states of consciousness: The transient hypofrontality hypothesis. Consciousness and Cognition, 12(2), 231-256. https://doi.org/10.1016/ s1053-8100(02)00046-6
Dietrich, A. (2004). Neurocognitive mechanisms underlying the experience of flow. Consciousness and Cognition, 13(4), 746-761. https://doi.org/10.1016/j.concog.2004.07.002

Dolcos, F., Bogdan, P. C., O’Brien, M., Iordan, A. D., Madison, A., Buetti, S., \& Dolcos, S. (2020). The impact of focused attention on emotional evaluation: An eye-tracking investigation. Emotion. https://doi.org/10.1037/emo0000895

Eisenberger, R., Jones, J. R., Stinglhamber, F., Shanock, L., \& Randall, A. T. (2005). Flow experiences at work: For high need achievers alone? Journal of Organizational Behavior, 26, 755-775. https:// doi.org/10.1002/job.337

Engeser, S. (2012). Comments on Schiefele and Raabe (2011): Flow is a multifaceted experience defined by several components. Psychological Reports, 111, 24-26. https://doi.org/10.2466/04.22. pr0.111.4.24-26

Engeser, S., \& Baumann, N. (2014). Does achievement motivation mediate the semantic achievement priming effect? Journal of Experimental Psychology: General, 143(5), 1861. https://doi. org/10.1037/a0036864

Engeser, S., \& Rheinberg, F. (2008). Flow, moderators of challengeskill-balance and performance. Motivation and Emotion, 32, 158-172. https://doi.org/10.1007/s11031-008-9102-4

Furr, R. M. (2017). Psychometrics: an introduction. Sage Publications.

Govern, J. M., \& Marsch, L. A. (2001). Development and validation of the situational self-awareness scale. Consciousness and Cognition, 10(3), 366-378. https://doi.org/10.1006/ccog.2001.0506

Hamilton, M., Kaltcheva, V. D., \& Rohm, A. J. (2016). Social media and value creation: The role of interaction satisfaction and interaction immersion. Journal of Interactive Marketing, 36, 121-133. https://doi.org/10.1016/j.intmar.2016.07.001

Hayes, A. F. (2018). Partial, conditional, and moderated moderated mediation: Quantification, inference, and interpretation. Соттиnication Monographs, 85(1), 4-40. https://doi.org/10.1080/03637 751.2017.1352100

Hu, L. T., \& Bentler, P. M. (1999). Cutoff criteria for fit indexes in covariance structure analysis: Conventional criteria versus new alternatives. Structural Equation Modeling: A Multidisciplinary Journal, 6(1), 1-55.

Huang, J. L., Bowling, N. A., Liu, M., \& Li, Y. (2015). Detecting insufficient effort responding with an infrequency scale: Evaluating validity and participant reactions. Journal of Business and Psychology, 30(2), 299-311. https://doi.org/10.1080/1070551990 9540118

Ilundáin-Agurruza, J. (2015). From clumsy failure to skillful fluency: A phenomenological analysis of and Eastern solution to sport's choking effect. Phenomenology and the Cognitive Sciences, 14(2), 397-421. https://doi.org/10.1007/s11097-014-9408-5

Jackson, D. L. (2003). Revisiting sample size and number of parameter estimates: Some support for the N: Q hypothesis. Structural Equation Modeling, 10(1), 128-141. https://doi.org/10.1207/ s15328007sem1001_6

Jantzen, C., Fitchett, J., Ø stergaard, P., \& Vetner, M. (2012). Just for fun? The emotional regime of experiential consumption. Marketing Theory, 12(2), 137-154. https://doi.org/10.1177/1470593112 441565

Kawabata, M., \& Mallett, C. J. (2011). Flow experience in physical activity: Examination of the internal structure of flow from a process-related perspective. Motivation and Emotion, 35(4), 393-402. https://doi.org/10.1007/s11031-011-9221-1

Kee, Y. H., \& Wang, C. J. (2008). Relationships between mindfulness, flow dispositions and mental skills adoption: A cluster analytic approach. Psychology of Sport and Exercise, 9(4), 393-411. https://doi.org/10.1016/j.psychsport.2007.07.001

Keller, J., \& Bless, H. (2008). Flow and regulatory compatibility: An experimental approach to the flow model of intrinsic motivation. 
Journal of Personality and Social Psychology Bulletin, 34, 196209. https://doi.org/10.1177/0146167207310026

Keller, J., Bless, H., Blomann, F., \& Kleinböhl, D. (2011b). Physiological aspects of flow experiences: Skills-demand-compatibility effects on heart rate variability and salivary cortisol. Journal of Experimental Social Psychology, 47(4), 849-852. https://doi.org/ 10.1080/17439760.2011.604041

Keller, J., Ringelhan, S., \& Blomann, F. (2011a). Does skills-demands compatibility result in intrinsic motivation? Experimental test of a basic notion proposed in the theory of flow-experiences. The Journal of Positive Psychology, 6(5), 408-417. https://doi.org/ 10.1080/17439760.2011.604041

Kim, T., \& Biocca, F. (1997). Telepresence via television: Two dimensions of telepresence may have different connections to memory and persuasion. Journal of Computer-Mediated Communication. https://doi.org/10.1111/j.1083-6101.1997.tb00073.x

Kulkarni, A., Anderson, W., Sanders, M. A., Newbold, J., \& Martin, L. L. (2016). Manipulated flow reduces downstream defensiveness. The Journal of Positive Psychology, 11(1), 26-36. https:// doi.org/10.1080/17439760.2015.1015157

Lau, M. A., Bishop, S. R., Segal, Z. V., Buis, T., Anderson, N. D., Carlson, L., Shapiro, S., Carmody, J., Abbey, S., \& Devins, G. (2006). The Toronto mindfulness scale: Development and validation. Journal of Clinical Psychology, 62(12), 1445-1467. https://doi.org/10.1002/jclp.20326

Lavoie, R., \& Main, K. (2019). Consumer microflow experiences. Psychology and Marketing, 36, 1133-1142. https://doi.org/10. 1002/mar.21262

Lavoie, R., \& Main, K. (2019). When losing time and money feels good: The paradoxical role of flow in gambling. Journal of Gambling Issues, 41, 53-72. https://doi.org/10.4309/jgi.2019. 41.4

Mandler, G., Nakamura, Y., \& Van Zandt, B. J. (1987). Nonspecific effects of exposure on stimuli that cannot be recognized. Journal of Experimental Psychology: Learning, Memory, and Cognition, 13(4), 646-648. https://doi.org/10.1037/0278-7393.13.4.646

Manly, T., Robertson, I. H., Galloway, M., \& Hawkins, K. (1999). The absent mind: Further investigations of sustained attention to response. Neuropsychologia, 37(6), 661-670. https://doi.org/10. 1016/s0028-3932(98)00127-4

Martin, A. J., \& Jackson, S. A. (2008). Brief approaches to assessing task absorption and enhanced subjective experience: Examining 'short' and 'core' flow in diverse performance domains. Motivation and Emotion, 32(3), 141-157. https://doi.org/10.1007/ s11031-008-9094-0

Mathwick, C., \& Rigdon, E. (2004). Play, flow, and the online search experience. Journal of Consumer Research, 31(2), 324-332. https://doi.org/10.1086/422111

McCrae, R. R., \& Costa, P. T. (1985). Openness to experience. In R. Hogan \& W. H. Jones (Eds.), Perspectives in personality (pp. 145-172). JAI Press.

Moller, A. C., Meier, B. P., \& Wall, R. D. (2010). Developing an experimental induction of flow: Effortless action in the lab. In B. Bruya (Ed.), Effortless attention: A new perspective in the cognitive science of attention and action (pp. 191-204). MIT Press.

Moneta, G. B. (2012). Opportunity for creativity in the job as a moderator of the relation between trait intrinsic motivation and flow in work. Motivation and Emotion, 36(4), 491-503. https://doi.org/ 10.1007/s11031-012-9278-5

Moneta, G. B. (2017). Validation of the short flow in work scale (SFWS). Personality and Individual Differences, 109, 83-88. https://doi.org/10.1016/j.paid.2016.12.033

Murphy, S., Patterson, M., \& O'Malley, L. (2018). Learning how: reflexive body techniques, skill acquisition, and the consumption of experience. Marketing Theory. https://doi.org/10.1177/14705 93118809792
Novak, T. P., Hoffman, D. L., \& Duhachek, A. (2003). The influence of goal-directed and experiential activities on online flow experiences. Journal of Consumer Psychology, 13(1-2), 3-16. https:// doi.org/10.1207/s15327663jcp13-1\&2_01

Novak, T. P., Hoffman, D. L., \& Yung, Y. (2000). Measuring the customer experience in online environments: A structural modeling approach. Marketing Science, 19(1), 22-42. https://doi.org/10. 1287/mksc.19.1.22.15184

Oppenheimer, D. M. (2008). The secret life of fluency. Trends in Cognitive Sciences, 12(6), 237-241. https://doi.org/10.1016/j.tics.2008. 02.014

Peifer, C., Schulz, A., Schächinger, H., Baumann, N., \& Antoni, C. H. (2014). The relation of flow-experience and physiological arousal under stress-Can u shape it? Journal of Experimental Social Psychology, 53, 62-69. https://doi.org/10.1016/j.jesp.2014.01.009

Reber, R., Winkielman, P., \& Schwarz, N. (1998). Effects of perceptual fluency on affective judgments. Psychological Science, 9(1), 45-48. https://doi.org/10.1111/1467-9280.00008

Rheinberg, F., Vollmeyer, R., \& Engeser, S. (2003). Die Erfassung des Flow-Erlebens The assessment of flow experience. In J. Stiensmeier-Pelster \& F. Rheinberg (Eds.), Diagnosis of motivation and self-concept (pp. 261-279). American Psychological Association. https://doi.org/10.1037/t47787-000

Ryan, R. M., \& Deci, E. L. (2000). Self-determination theory and the facilitation of intrinsic motivation, social development, and wellbeing. American Psychologist, 55(1), 68. https://doi.org/10.1037/ 0003-066x.55.1.68

Schiefele, U. (2013). Response to Engeser (2012): On the nature of flow experience. Psychological Reports. https://doi.org/10.2466/ 04.pr0.112.2.529-532

Schiefele, U., \& Raabe, A. (2011). Skills-demands compatibility as a determinant of flow experience in an inductive reasoning task. Psychological Reports, 109, 428-444. https://doi.org/10.2466/04. 22.pr0.109.5.428-444

Schüler, J. (2010). Achievement incentives determine the effects of achievement-motive incongruence on flow experience. Motivation and Emotion, 34(1), 2-14. https://doi.org/10.1007/ s11031-009-9150-4

Schüler, J., Brandstätter, V., \& Sheldon, K. M. (2013). Do implicit motives and basic psychological needs interact to predict wellbeing and flow? Testing a universal hypothesis and a matching hypothesis. Motivation and Emotion, 37(3), 480-495. https://doi. org/10.1007/s11031-012-9317-2

Schwarz, N. (2004). Metacognitive experiences in consumer judgment and decision making. Journal of Consumer Psychology, 14, 332-348. https://doi.org/10.1207/s15327663jcp1404_2

Sheldon, K. M., Prentice, M., \& Halusic, M. (2015). The experiential incompatibility of mindfulness and flow absorption. Social Psychological and Personality Science, 6(3), 276-283. https://doi. org/10.1177/1948550614555028

Sheridan, T. B. (1992). Musings on telepresence and virtual presence. Presence: Teleoperators \& Virtual Environments, 1(1), 120-126. https://doi.org/10.1162/pres.1992.1.1.120

Sidarus, N., Vuorre, M., Metcalfe, J., \& Haggard, P. (2017). Investigating the prospective sense of agency: Effects of processing fluency, stimulus ambiguity, and response conflict. Frontiers in Psychology, 8, 545. https://doi.org/10.3389/fpsyg.2017.00545

Smallwood, J., \& Schooler, J. W. (2006). The restless mind. Psychological Bulletin, 132(6), 946. https://doi.org/10.1037/0033-2909. 132.6.946

Smith, D. N., \& Sivakumar, K. (2004). Flow and Internet shopping behavior: A conceptual model and research propositions. Journal of Business Research, 57(10), 1199-1208. https://doi.org/10.1016/ s0148-2963(02)00330-2

Song, H., \& Schwarz, N. (2009). If it's difficult to pronounce, it must be risky: Fluency, familiarity, and risk perception. Psychological 
Science, 20(2), 135-138. https://doi.org/10.1111/j.1467-9280. 2009.02267.x

Teasdale, J. D., Moore, R. G., Hayhurst, H., Pope, M., Williams, S., \& Segal, Z. V. (2002). Metacognitive awareness and prevention of relapse in depression: empirical evidence. Journal of consulting and Clinical Psychology, 70(2), 275. https://doi.org/10.1037/ 0022-006x.70.2.275

Teng, C. I. (2011). Who are likely to experience flow? Impact of temperament and character on flow. Personality and Individual Differences, 50(6), 863-868. https://doi.org/10.1016/j.paid.2011.01.012

Trevino, L. K., \& Webster, J. (1992). Flow in computer-mediated communication. Communication Research, 19, 539-573. https://doi. org/10.1177/009365092019005001

Van Laer, T., De Ruyter, K., Visconti, L. M., \& Wetzels, M. (2014). The extended transportation-imagery model: A meta-analysis of the antecedents and consequences of consumers' narrative transportation. Journal of Consumer Research, 40(5), 797-817. https:// doi.org/10.1086/673383

Van Laer, T., Edson Escalas, J., Ludwig, S., \& Van Den Hende, E. A. (2019). What happens in Vegas stays on TripAdvisor? A theory and technique to understand narrativity in consumer reviews. Journal of Consumer Research, 46(2), 267-285. https://doi.org/ 10.1093/jcr/ucy067

Watson, D., Clark, L. A., \& Tellegen, A. (1988). Development and validation of brief measures of positive and negative affect: The PANAS scales. Journal of Personality and Social Psychology, 54(6), 1063. https://doi.org/10.1037/0022-3514.54.6.1063
Weibel, D., Wissmath, B., Habegger, S., Steiner, Y., \& Groner, R. (2008). Playing online games against computer-vs. human-controlled opponents: Effects on presence, flow, and enjoyment. Computers in Human Behavior, 24(5), 2274-2291. https://doi.org/10. 1016/j.chb.2007.11.002

Winkielman, P., Schwarz, N., Fazendeiro, T., \& Reber, R. (2003). The hedonic marking of processing fluency: Implications for evaluative judgment. The Psychology of Evaluation: Affective Processes in Cognition and Emotion. https://doi.org/10.4324/9781410606 853-14

Wolf, E. J., Harrington, K. M., Clark, S. L., \& Miller, M. W. (2013). Sample size requirements for structural equation models: An evaluation of power, bias, and solution propriety. Educational and Psychological Measurement, 73(6), 913-934. https://doi.org/10. $1177 / 0013164413495237$

Yong, A. G., \& Pearce, S. (2013). A beginner's guide to factor analysis: Focusing on exploratory factor analysis. Tutorials in Quantitative Methods for Psychology, 9(2), 79-94. https://doi.org/10.20982/ tqmp.09.2.p079

Publisher's Note Springer Nature remains neutral with regard to jurisdictional claims in published maps and institutional affiliations. 